\title{
Emerging environmental and educational service of dairy farming in Japan: dilemma or opportunity?
}

\author{
Y. Ohe \\ Department of Food and Resource Economics, Chiba University, Japan
}

\begin{abstract}
Multifunctionality in agriculture indicates the performance of various functions of positive externalities. However, unless these externalities are internalized in farming activity, they will not be sustainable over the long term. In the livestock farming arena, a program was started in Japan in 2000 whereby dairy farmers would offer farm experiences mainly to youngsters. Although this service is considered to be a by-product of dairy farming with positive externalities, this subject has received minimal attention. Therefore, this paper sheds light on how dairy farmers cope with this new situation by empirically examining national survey data on this activity, presenting study cases, and conceptualizing problems and ways to find solutions. The main findings were as follows:

1) Dairy farms providing farming experiences play a positive role in teaching about farm life, how food is produced and the stress relief provided by the rural environment, especially for compulsory school-age children at elementary and junior high schools in local communities. To cope with the rising number of visitors, minimal necessary facilities such as toilets should be prepared.

2) Farming experiences have an educational effect not only on visitors, but also on the farmers themselves. This is because farmers can discover new possibilities for agriculture, which eventually leads to a deepening realization of new environmental and educational services that benefit society.

3) However, it is often difficult for farmers to harmonize the provision of the service of a farming experience to visitors with performance of their own farming activity. Farmers often face the dilemma of whether to offer farming experience services on a voluntary basis free of charge or to sell such services as a new farm product, such as traditional milk products, in exchange for money. Therefore, it is necessary to raise the social recognition of the educational function generated by those farmers who provide farming experience services.

Keywords: multifunctionality in agriculture, externality, educational function, internalization, environmental and educational services of dairy farming, farm diversification, sustainable rural-urban relationship.
\end{abstract}




\section{Introduction}

Multifunctionality in agriculture exerts externality that benefits society and includes various sub-functions (Brouwer [2], OECD [3, 4], Pezzini [8], Van Huylenbroeck and Whitby [11], Van Huylenbroeck and Durand [12], Tabuchi and Siomi [10], Ohe [7]). Among these functions, the educational sub-function of farming has been recognized as providing a significant educational experience (Shichinohe et al [9]).

It is expected that the educational function in farming plays an increasingly important role in easing stress of people caught up in the modern urban lifestyle and in complementing educational capabilities of the household and local community in terms of education on food, the rural heritage and the rural environment. Thus, an educational function is considered as a new role of agriculture in society.

However, little has been investigated empirically on this educational function. Ohe [6] investigated the educational function of dairy farms and found that this function was not connected with farm size. A preceding study on educational farms showed that launching an educational farm does not require major investments in the facility compared with rural tourism activities that require investment in lodging facilities. Because of this, an educational farm is relatively easy to begin for farmers (Oshima [5]). To our knowledge, the demand side has not been examined at all.

On the other hand, economic analyses on education and the educational system have increased recently. However, these studies did not focus on the educational function as a joint product of farming or other economic activities, but on the educational system in general or student behaviour related to higher education from the human capital and/or signalling theories (Arai [1]). Essentially, there has been little investigation on how to position this function into farm activity from a farm policy perspective, especially in relation to rural and farm diversification taking into account multifunctionality.

Concerning the educational function in farming, dairy farming is most advanced in making this function a reality. The program for educational dairy farms started in 2000 in Japan, which means that incorporating the educational function into farming practically began through providing the service of a dairy farming experience. However, since the significance of a farming experience service is not widely known in society, its position as a farm activity has not yet been well defined.

The purpose of this paper is to examine some of the issues related to this new farming activity. First, this paper provides an overview of educational dairy farms, explains what they are doing and who demands this service in what way. Second, we illustrate within an economic framework how to properly position the educational function into farm activity from two case studies. Finally, we consider the policy measures that are necessary so that the educational function of farming can take root in society. 


\section{What is an educational dairy farm?}

Educational dairy farms as designated are not only operated by individual dairy farmers, but also can be corporate farms, such as public or private ranches. As of 2003, 167 farms were designated as educational dairy farms, which is about $0.5 \%$ of the total dairy farms in this country. The number of designated farms is increasing annually. To qualify, the farmers themselves or their families or employees must take part in a seminar to obtain this designation. The Japan Dairy Council certifies those farms that completed the seminar after examination of the application form.

Besides attending the seminar, farms must do the following: 1) provide visitors with toilets and hand-washing facilities, 2) prepare emergency medical kits, 3) be located near medical institutions and make such institutions aware of their operation, 4) have insurance against damage to the facilities or injuries to visitors, and 5) observe safety and hygiene standards. Especially, damage insurance is of importance to both farmers and visitors in the event of personal injury or property damage. Now let us examine the details of the activities of these farms.

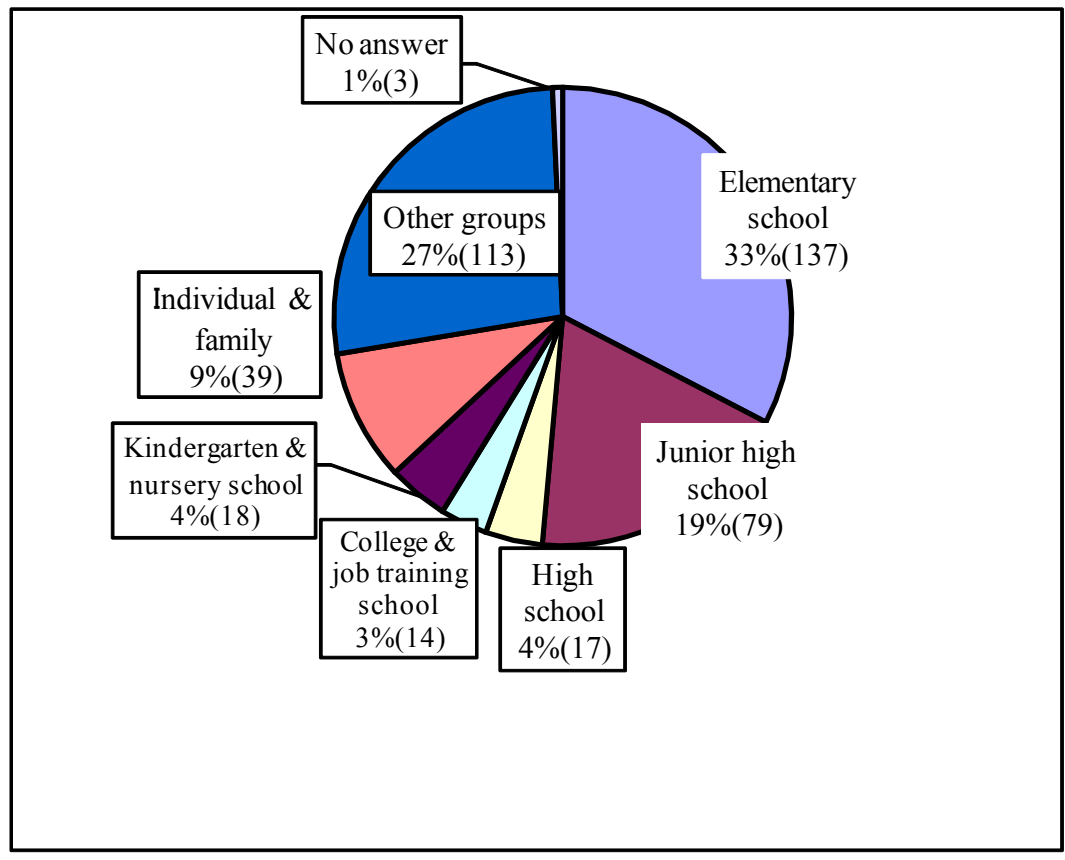

Figure 1: Visitor affiliations. (Note: as of year 2002, Japan Dairy Council. Sample size in brackets.)

Figure 1 illustrates the composition of visitor affiliations as reported by the Japan Dairy Council for 2002 and shows that one third of visitors were from elementary schools and about one fifth from junior high schools. Therefore, over 
half of the visitors were from compulsory education institutions. This means that these farms contributed to the local community in sharing an educational role in the compulsory education system.

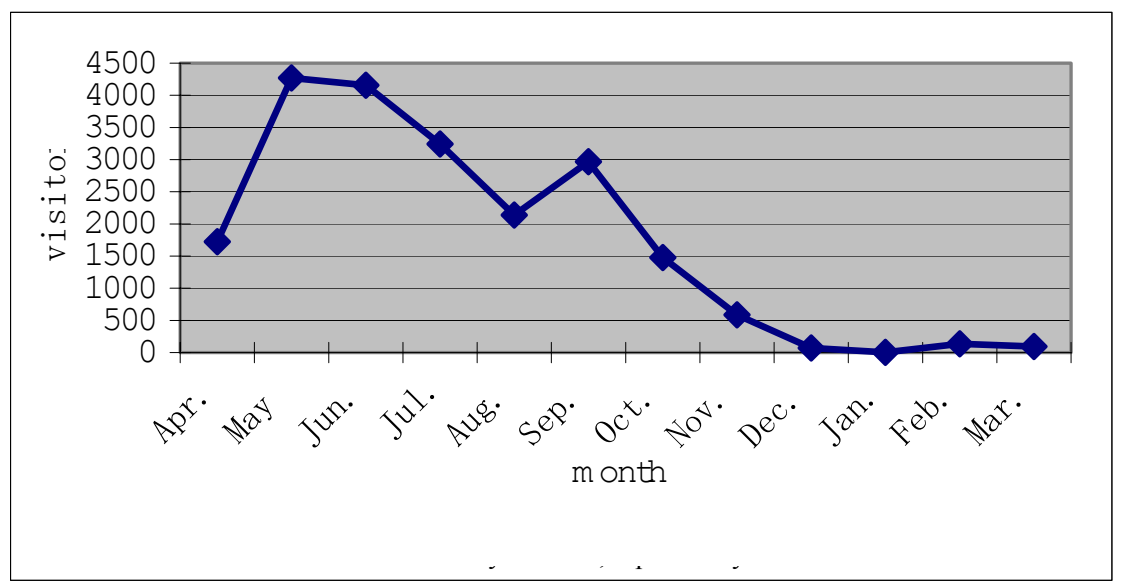

Figure 2: Monthly number of visitors. (Note: as of year 2002, Japan Dairy Council.)

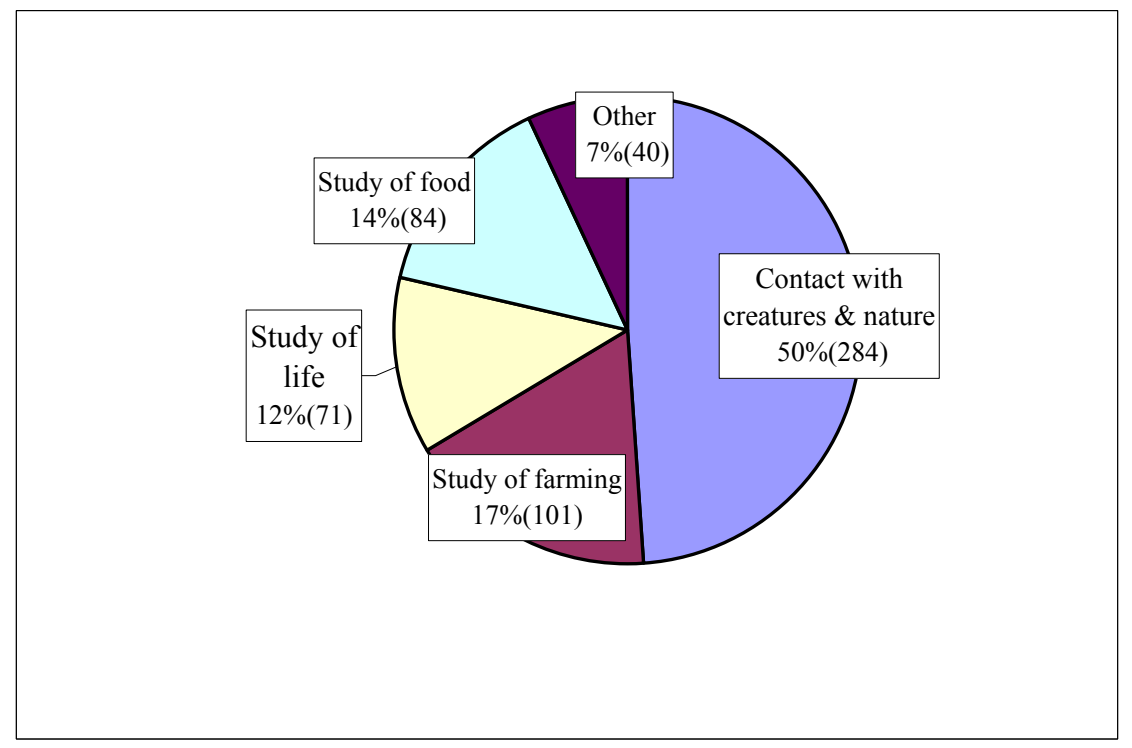

Figure 3: Purpose of visit: multiple answers. (Note: as of year 2002, Japan Dairy Council. Sample size in brackets.) 
Figure 2 shows monthly attendance. The highest attendance is during the first part of the school year, that is, in May, June and July. Although we have a rainy season from June to July in Japan, visitors can experience dairy farming practices indoors. This is an advantage of livestock farming compared with crop farming. September and October is the second busiest season, while, in contrast, there are few visitors in the winter season from December onward. Thus, the early summer is the most suitable time for farming experiences.

As to the purpose of the farm visit, whereas more than $50 \%$ answered that the purpose was contact with animals, less than $20 \%$ stated the study of farming as the purpose (Figure 3). This means that multifunctionality of agriculture stimulated interest for farm visits rather than farming per se. In other words, the purpose of farm visits tells us where the educational function of agriculture originates. In this respect, taking into account multifunctionality is a necessary condition to enhance the educational function of agriculture.

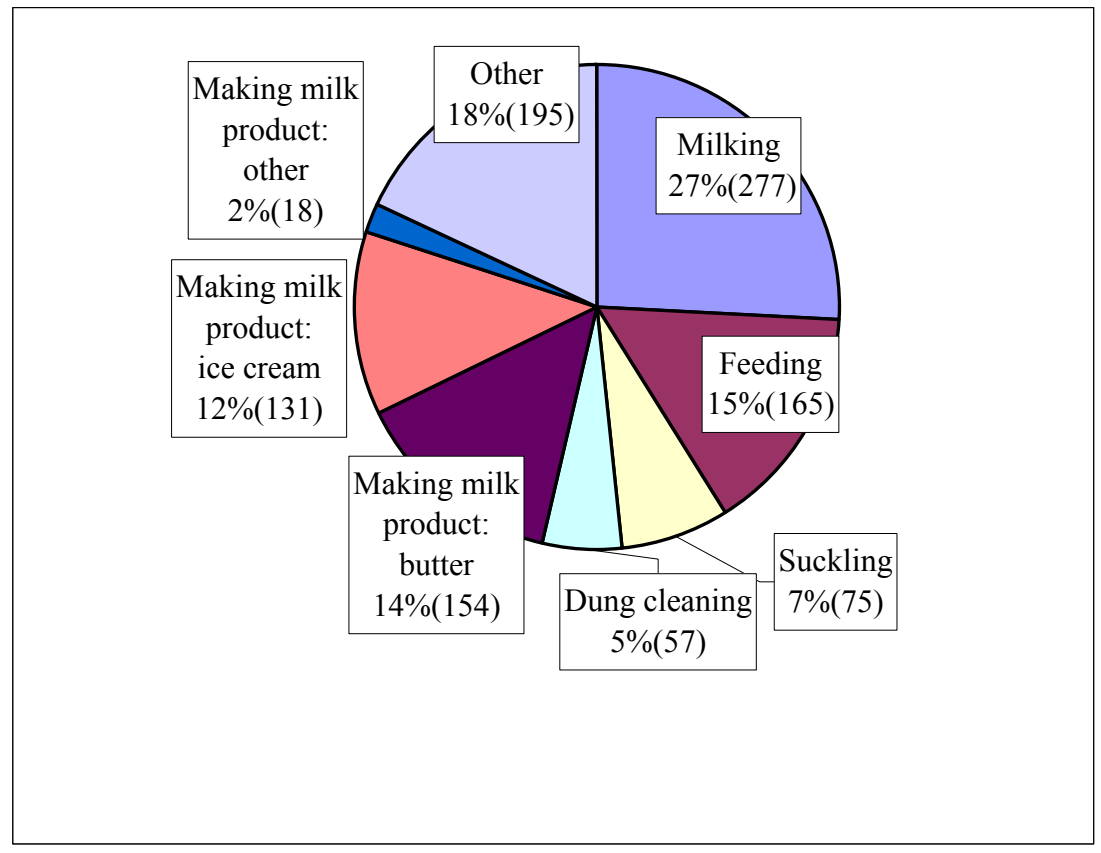

Figure 4: Content of farming experience: multiple answers. (Note: as of year 2002, Japan Dairy Council. Sample size is in brackets.)

The content of the farming experience was divided into two categories: dairy operations and dairy products (Figure 4). Visitors usually are exposed to experiences in several service areas, so that there were multiple answers. Milking and feeding were common menu items among operations while making butter and ice cream were the first and the second common among products. Making dairy products is an important menu item related to experience in terms of raising interest in food as a means of food education. 
The most frequent complaint was lack of sufficient toilets. This problem becomes serious when large groups visit farms because the long lines hinder smooth implementation of the farming experience.

In summary, the significance of providing farming experiences in dairy farms was recognized especially by the compulsory education system. Experiences in the farm yard result in providing education on farming and food for visitors whereas the initial motivation for the farm visitors was interest in multifunctionality rather than for farming per se. Facility-wise, adequate toilet facilities should be prepared.

\section{Case studies of educational dairy farms}

The two dairy farmers studied here did not consider providing farming experience services as a full-time economic activity. Rather, they thought that their offering those services was a volunteer activity to benefit the local community. In this sense, it is safe to say that they aimed to establish mutual long-term trust with the local community.

\subsection{Case 1: services provided free of charge}

Mr Y. Kameda receives mainly junior high school students in Sakado, a northwestern suburb of the metropolitan area. He does this because he wants his dairy farm to be supported and considered necessary to the local community. $\mathrm{He}$ believes that the educational function in the local community has become increasingly necessary to compensate for the declining function of the traditional family educational role. However, a major problem of performing this activity is that it takes many hours to complete the planned program of activities. He has not yet received any monetary reward for this service. He feels that it will be difficult to maintain the same attitude in the future because the requests to visit his farm are rising.

\subsection{Case 2: services provided for a fee}

Mrs Y. Sudo is another example of this type of dairy farmer in Tateyama, the southern tip of Chiba prefecture. She also feels that without doubt the demand for farm visits and for farming experiences has risen in the last decade. However, she also thinks that social recognition for this service is still low. Therefore, to gain the acknowledgement that she appropriately feels is deserved, she believes that dairy farmers should outgrow the role of volunteer. For that reason, she discloses service fees and charges for the services that her farm provides. However, she does not intend to seek profit from this activity or to be a tourism ranch.

In short, providing farming experience services is a new activity for farmers and farmers are still seeking how to position this new activity within each farm. However, there is no reason why the demand for this new activity will not grow because modern urban life has become more and more stressful. There should be something to ease the stress. The first factor that the two farmers have in 
common is that they actively seek a new role for dairy farming in connection with their local communities. The second common point is their conviction that this new role is closely connected to the multifunctionality of farming and that the significance of this role is growing. That is why it is necessary to increase social recognition of their new activity.

\section{Toward internalizing the external effect of farming experience services}

\subsection{Two external effects}

As mentioned above, educational dairy farms exert externalities on the local community. However, this situation cannot be resolved for either farmers or society by farmers simply asking payment from visitors. This is because we should take into account the relationship between farmers and the local community. We consider that this relationship contains two types of externalities that are mingled. Thus, we attempt here to clarify how to realize the internalization process by taking into account these two effects. We call them the neighbourhood effects, which are subdivided into the first effect and the second effect.

\subsection{First effect: collectable by farmers}

The first effect is characterized by the fact that farmers do not internalize it for the local community but use it to build trust from the local community. This behaviour means that they obtain intangible compensation in the form of trust in exchange for taking care of local elementary and junior high school students from the perspective of nurturing community resources. In this sense it can be said that they try to internalize the externality by attaining trust with the local community from the long-term perspective. Then once a trustful relationship is established, even if there are troublesome episodes such as annoying complaints or complaints related to noise pollution by livestock, local residents would understand the farming activity and would not file any serious complaints. This means that transaction costs with the local community would be minimized. Thus, we can say that this offered farming experience contributes to community resources in the form of trust.

Moreover, in addition to minimizing the transaction cost with the local community, there is another important point. That is the discovery of a new role for farming people and thereafter formation of a new identity for farmers. This results in improving the quality of service that farmers provide and eventually in the integration of the whole farm activity. However, in any case, these efforts by farmers will not be paid for in the short term, but will be paid for over the long term by gaining trust from the local community, which is a form of long-term insurance. 
Thus, the above effect is rational economic behaviour from the farm management point of view as a going concern. These costs are internalized in any case, although there is variation in the degree of this internalization from one farm to another. However, the problem is that the cost that farmers have to carry is not limited to the costs mentioned above. That is why we should consider another effect next.

\subsection{Second effect: uncollectable for farmers}

The second effect is also caused by the relationship with the local community. Particularly when the demand for the farming experience increases, so does the burden for farmers in terms of time spent for coordination and preparation to accept visitors. This entire process takes opportunity costs as foregone income. The issue is that farmers feel hesitant in asking for visitors to pay for these preparation costs due to their sense of neighbourliness with the local community. In other words, on the farmers' part, excess supply of farming experience services is offered to the local community. This is a truly positive externality brought by farmers to the local community. In this sense it can be designated as an over-commitment effect to the neighbourhood or strictly speaking the neighbourliness effect. This effect has an ironic aspect; the more a sense of neighbourliness a farmer has, the more difficult the cost is to collect. Because generally those who start this activity originally have a volunteer spirit, it is difficult for them to ask the local people to cover these costs. Thus, the closer to the neighbours, the more difficult it is for farmers to collect unpaid costs. In this sense, it can be said that it is an externality that has a neighbourhood effect. This is a situation where a farmer is forced to provide over-supply on one hand and the local residents take a free ride without paying the cost on the other hand.

In short, we can classify the externality created by providing farming experience services as shown below:

1. Investment in forming trust with the local community; collectable in the long run.

2. Over-supply from the sense of neighbourhood; not collectable for farmers.

The composition of the two differs from one farmer to another, depending on the farmer's attitude toward this new activity. In any case, the cost that farmers do not collect in the short term includes these two types of cost.

While the first behaviour to gain trust is rational as farm activity, the second neighbourhood effect is not rational, which will raise disutility for providers, although the degree will depend on their attitude toward this activity. From an economic perspective of socially optimal resource allocation, externality that is difficult to internalize by farmers is the second case. The problem here is that if the second effect becomes too large, it will eventually discourage farmers from continuing to provide farming experience service.

To examine this point further we built an economic framework on how to deal with the educational function of farming, which is described in the next chapter. 


\section{Economic framework}

Here for simplicity we assume that only local residents are demanding farming experience services. Figure 5 illustrates the demand curve and the supply curve of farming experience, measuring horizontally the level of farming experience services and vertically the value of such services. Curve $c p_{1}$ represents the private marginal cost of producing a farming experience service, curve $c p_{2}$ is the private marginal cost when cost of forming trust from the local community is taken into account, and curve $c s$ is the social marginal cost of the farming experience service.

These curves become one identical horizontal line at the low level of farming experience service. This is because providing a farming experience service does not require any additional cost due to its characteristic of a joint product with dairy production. Therefore, to a certain extent, depicted as point $k$ in Figure 5, even if demand increases up to this level, the price remains low. At this stage, in response to the small size of demand as depicted in demand curve $d_{0} d^{\prime}{ }_{0}$, for instance, at the point where the price is very low as shown at $o c$, it is easy to reach an equilibrium even with something like a small gift brought by visitors, such as home-made cookies.

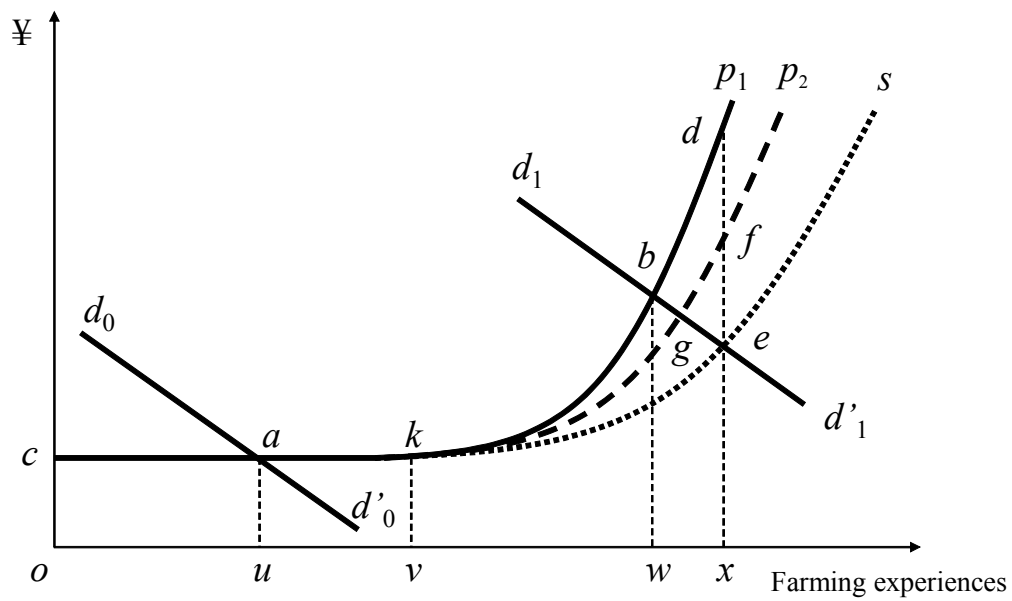

Figure 5: Conceptual model of farming experience service.

However, at the stage when demand increases beyond point $k$, the curve begins to move upward and branches off into three curves. In these areas, the farmer begins providing full-scale farming experience services and consequently generates the positive externality as the educational function for local communities. Because of this externality, the social marginal cost curve $c s$ is always under the private marginal cost curves $c p_{1}$ and $c p_{2}$. 
Suppose the demand increases to demand curve $d_{1} d^{\prime}{ }_{1}$, the local society does not recognize this externality, which means that visitors do not consider the social marginal cost curve $c s$ while farmers recognize that cost. In short, there is asymmetry of information between farmers and local visitors or residents. This information gap results in excessive demand at $o x$ for farming experience services without paying the cost. However, the demand $o x$ is at a socially optimal level only when the social marginal cost is borne by visitors. This is not the case in reality because farmers face the private marginal cost curve rather than the social marginal cost curve. This private marginal cost increases as production of the farming experience service increases. The reason why the curve is right and upward is that the transaction cost for providing farming experience service increases along with increases in the service offered. The transaction cost includes opportunity cost for coordination of the farming operation and visitors and for preparation while taking into account labour allocation between the farming operation and providing visitor services. As far as farming experience services are concerned, farmers must deal with coordination and preparation themselves, unlike in the case of traditional farm products where division of labour is possible through use of shipping and marketing organizations such as agricultural cooperatives. This burden results in lowering labour productivity in the dairy farming operation and eventually further raises the opportunity cost for providing the farming experience service. This is the reason that the private marginal curve moves steeply upward.

Therefore, the private optimal point for farmers is at point $b$ where it is rational for them to provide the service to ow. However, local community demands rise to $o x$, a point where farmers cannot refuse and then must provide the service. This is not a social optimal point because if visitors pay the amount of $d e$, a social optimal point is attained at point $e$ instead of $b$. However, that is not the case in reality, since visitors do not pay. When the amount of de is not paid to farmers by local beneficiaries due to the unrecognized social marginal cost curve $c s$, the private marginal cost reaches point $d$ for the farming experience service at $o x$.

The amount of $d f$ out of the unpaid amount of $d e$ will be able to be internalized for farmers as trust forming, and $f e$, the rest of the $d e$, is difficult to be internalized due to the neighbourhood effect that makes it difficult for farmers to ask for payment.

When local communities become dependent on these farming experience services, the demand curve becomes inelastic or more steeply sloped. For comparison, suppose that the inelastic demand curve crosses at point $e$ with the social marginal cost curve $c s$. Then some of the unpaid portion is shifted on to the demand side, so the difference between the private optimal supply ow and the social optimal supply $o x$ will be reduced. In this respect, inelastic demand is preferable for farmers and from the social resource allocation viewpoint as well. However, even if the difference will be reduced, the difference remains unless the demand becomes perfectly inelastic, which rarely happens in reality. Thus, whereas making the demand inelastic will be one solution for the externality, we should recognize that it is not the perfect solution. 
It can be said that originally the farming experience service by farmers was born as a complement or substitute for the educational capability of the family and local community, which is in decline. In view of this, the amount of the unpaid portion or the over-commitment effect $f e$ should be as small as possible in order to ensure sustainable provision of this service. However, these activities are not yet fully recognized socially, so farmers end up providing excessive service in taking into account the neighbourhood relationship. Particularly, those farmers that provide this service tend to be highly motivated to perform volunteer work and they willingly meet this challenge. However, they face the dilemma that the greater the love of the community, the larger is the unpaid portion by excessive supply of service. Eventually it becomes difficult to continue providing the service.

Therefore, to maintain this educational function and develop it sustainably, it is necessary to build a social system so that the demand side should not remain a free rider of the externality provided by farmers. To this end, first, measures should be taken to widely inform society of this educational function in farming to resolve the information asymmetry between farmers and the rest of the society, particularly the local community. Second, in taking into account the large number of compulsory education institutions that are beneficiaries, a certain part of the unpaid portion should be paid as an investment in education or be considered a necessary educational cost and be paid from the budget of the local government. Moreover, also, it will be necessary to seek a third body to assume an intermediary coordinating role between farmers and visitors to reduce the transaction cost for farmers.

\section{Conclusions}

This paper explored economic conditions for increasing the educational function of agriculture by focusing on educational dairy farms that provide farming experience services in Japan. The main findings were as follows:

1) Educational dairy farms play a positive role by offering farming experience especially for compulsory school-age children, such as those in elementary and junior high schools in the local community. To cope with the rising number of visitors, at a minimum, necessary facilities such as toilets should be adequately provided.

2) Farming experiences have educational effects not only on visitors, but also on farmers per se. This is because farmers can discover new possibilities in agriculture, which eventually leads to deepening and further realizing multifunctionality.

3) Regarding the relationship with local communities, the farmers were not able to demand payment for providing services because they felt a sense of closeness to the local community. The main reason for this situation of under-charge comes from the asymmetric flow of information between farmers and the rest of society. Therefore, supporting measures enhancing the social recognition of the external effect caused by those farmers who provide farming experience services should be taken into account in the future. This is the first step to nurture a new role of agriculture that contributes to a sustainable rural-urban relationship. 


\section{References}

[1] Arai, K. The Economics of Education, Springer-Verlag: Tokyo, 1998.

[2] Brouwer, F. (eds) Sustaining Agriculture and the Rural Environment: Governance, Policy and Multifunctionality, Edward Elgar Publishing Ltd.: Cheltenham, 2005.

[3] OECD. Multifunctionality: Towards an Analytical Framework, OECD: Paris, 2001.

[4] OECD, Multifunctionality: The Policy Implications, Paris, 2003.

[5] Oshima, J. Educational Farm in France (in Japanese), Japan Education Press: Tokyo, 1999.

[6] Ohe, Y. Evaluating Jointness of Multifunctional Agriculture: Educational Function of Dairy Farming in Japan, Aravossis, K., Brebbia, C. A., Kakaras, E. and Kungolos, A. G. (eds) Environmental Economics and Investment Assessment, WIT Press: Southampton, pp.337-346, 2006.

[7] Ohe, Y. Multifunctionality and Rural Tourism: A Perspective on Farm Diversification, Journal of International Farm Management, in press.

[8] Pezzini, M. Rural Policy Lessons from OECD Countries. Paper Presented in the International Conference, European Rural Policy at the Crossroads, University of Aberdeen, Aberdeen, 2000.

[9] Shichinohe, C., Nagata, K. and Jinnouchi, Y. Educational Function of Agriculture (in Japanese), Rural Culture Association: Tokyo, 1990.

[10] Tabuchi, Y. and Siomi, M. Mountainous Areas and Multifunctionality (in Japanese), Association of Agriculture and Forestry Statistics: Tokyo, 2002.

[11] Van Huylenbroeck, G. and Whitby, M. Countryside Stewardship: Farmers, Policies and Markets. Elsevier Science Ltd: Oxford, 1999.

[12] Van Huylenbroeck, G. and Durand, G., Multifunctional Agriculture: A New Paradigm for European Agriculture and Rural Development, Ashgate Publishing Ltd.: Aldershot, 2003. 